\title{
REVISTAMARACANAN
}

Dossiê

\section{A crença no Profeta: uma abordagem crítica das memórias de Samuel Wainer}

\author{
The belief in the Prophet: a critical approach to the memoirs of Samuel \\ Wainer
}

\author{
Mariana Dias Antonio* \\ Universidade Federal do Paraná, Brasil \\ Marcella Lopes Guimarães** \\ Universidade Federal do Paraná, Brasil
}

Recebido em: 30 dez. 2018.

Aprovado em: 22 abr. 2019.

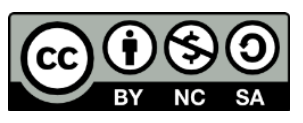

O presente trabalho foi realizado com apoio da Coordenação de Aperfeiçoamento de Pessoal de Nível Superior - Brasil (CAPES) - Código de Financiamento 001.

\footnotetext{
* Doutoranda em História pela Universidade Federal do Paraná (UFPR), com bolsa CAPES. Mestra em História pela UFPR e Licenciada em História pelo Centro Universitário Dr. Edmundo Ulson. (mariana.diasant@gmail.com)

ORCID iD: http://orcid.org/0000-0002-4596-2399

CV Lattes: http://lattes.cnpq.br/3014949770055190

** Professora Associada da Universidade Federal do Paraná (UFPR). Doutora em História pela UFPR; Mestra em Letras (Letras Vernáculas) e graduada em Letras pela Universidade Federal do Rio de Janeiro. (marcella974@gmail.com)

CV Lattes: http://lattes.cnpq.br/6266619466834133
} 


\title{
Resumo
}

Minha Razão de Viver, autobiografia do jornalista Samuel Wainer, é um livro comumente utilizado em cursos e pesquisas acadêmicas que abordam a imprensa ou a política do Brasil contemporâneo, às vezes levando ao uso acrítico de dados e eventos pontuais presentes em sua narrativa. Buscamos fornecer uma visão geral crítica a partir de alguns casos pontuais, confrontando o relato autobiográfico e outras fontes, documentais e/ou bibliográficas. Embora os casos aqui trazidos e confrontados não esgotem as diversas possibilidades contidas em Minha Razão de Viver, o presente trabalho demonstra a necessidade constante de validação dos conteúdos trazidos nas histórias de vida.

Palavras-chave: Samuel Wainer. Autobiografia. Ultima Hora.

\begin{abstract}
Minha Razão de Viver [My Reason for Living], autobiography of the journalist Samuel Wainer, is a commonly used book in academic courses and researches on the Brazilian contemporary politics and press, sometimes leading to the uncritical use of punctual data and events present in its narrative. We aim to provide a critical overview of some specific cases, comparing the autobiographical account and other sources, documentary and/or literary. Although the cases here brought and confronted do not exhaust the diverse possibilities contained in Minha Razão de Viver, this work shows the constant need of validation of the life stories' contents.
\end{abstract}

Keywords: Samuel Wainer. Autobiography. Ultima Hora. 


\section{Introdução}

Enquanto narrativas ou registros históricos, biografias são amplamente utilizadas por historiadores, sociólogos e outros pesquisadores das humanidades. Observada a aparente facilidade que impõem ao pesquisador, por compilarem diversos fatos, eventos e episódios num todo coeso e orgânico, a extração mais ou menos acrítica e sem atenção aos métodos e expectativas a partir dos quais a narrativa foi construída pode resultar em ruídos e inconsistências. Além da atenção aos métodos e expectativas, o historiador François Dosse atenta que é preciso levar em conta "o polo imaginativo do biógrafo" em tensão com a "vontade de reproduzir um vivido real passado". ${ }^{1}$ Para Dosse, a biografia não é o único gênero historiográfico a sofrer dessa tensão, mas segundo o autor ela pode ser elevada ao paroxismo, devido ao seu hibridismo, proximidade com a ficção e importação de técnicas mesmas da ficção narrativa. O desafio atravessa a autobiografia, ou seja, a exploração narrativa da vida do sujeito que é a um só tempo narrador e protagonista. Dosse categoriza diferentes formas e possibilidades de escrita biográfica: Heroica, Modal, Hermenêutica e Intelectual; sendo importante salientar que estas modalidades não são estanques, tampouco fixas, havendo a possibilidade de biografias ou autobiografias híbridas, apresentando mais de uma forma. ${ }^{2}$

Ruídos inerentes às narrativas biográficas já foram levantados em variadas áreas do conhecimento. No âmbito historiográfico, François Dosse alerta para o realce constante das mesmas personagens na escrita biográfica com a prerrogativa de que novos documentos e novas perguntas e respostas podem surgir a todo instante, preenchendo lacunas que outrora foram mantidas. Dosse aponta que, assim como a História, a biografia se escreve primeiramente no presente, "numa relação de implicação ainda mais forte quando há empatia por parte do autor". ${ }^{3}$ A partir disto, o mesmo deve-se atentar para não fazer desta narrativa um discurso de autenticidade pleno do indivíduo biografado, considerando a impossibilidade de descrever uma história de vida total. ${ }^{4}$ Em certos casos, até mesmo autobiografias (póstumas ou não) se submetem a um editor que seleciona determinados trechos de um relato em detrimento de outros, ilustrando a empatia também do editor que participa na construção da obra a ser publicada.

Já no âmbito sociológico, Pierre Bourdieu critica a noção de "história da vida" a partir do senso comum, que vê a escrita biográfica como uma sucessão de eventos cronologicamente e logicamente ordenados e mais ou menos linear, como um percurso ou caminho, ignorando diversas influências sociais que interferem nessa trajetória. Também se critica a orientação da

\footnotetext{
${ }^{1}$ DOSSE, François. O desafio biográfico: escrever uma vida. Trad.: Gilson César Cardoso de Souza. São Paulo: Ed. USP, 2009, p. 55.

${ }^{2}$ Idem.

${ }^{3}$ Ibidem, p. 11.

${ }^{4}$ Ibidem, p. 14.
} 
narrativa a um objetivo ou realização, e a aceitação tácita entre biógrafo e biografado acerca do sentido daquela vida, que implica na seleção de acontecimentos significativos de acordo com uma intenção global. Bourdieu pontua ainda instituições sociais de unificação do indivíduo, como o nome próprio, que mantêm a constância diacrônica (mesmo indivíduo em diferentes momentos) e a unidade sincrônica (mesmo indivíduo em diferentes contextos sociais no mesmo momento) ${ }^{5}$ estando estes entre alguns elementos de seu texto que levariam a críticas como as de François Dosse, para quem a argumentação bourdieusiana visaria invalidar o registro biográfico. ${ }^{6}$ Para aliviar a tensão entre uma suposta identidade substancial e a variação de identidades e identificações imposta pelo fluxo do devir, o conceito de identidade narrativa proposto por Paul Ricoeur permitiria uma via alternativa de encarar o registro biográfico sem invalidá-lo ou desconsiderá-lo totalmente. A identidade narrativa seria o reconhecimento do sujeito nas histórias que se contam sobre si, e permitiria tratar simultaneamente da mesmidade e da ipseidade, da permanência e da mudança. ${ }^{7}$

Restringindo o escopo às narrativas autobiográficas, Bourdieu destaca uma espécie de busca em atender às demandas específicas de determinado mercado de bens simbólicos: os relatos se modificam em diferentes contextos, como numa conversa entre amigos, num interrogatório policial e numa entrevista de emprego. ${ }^{8} \mathrm{~A}$ formalização dessas narrativas não se sujeita apenas às demandas externas de um mercado de bens simbólicos, sendo importante levar em conta a interiorização de estruturas e influências sociais enquanto realidade subjetiva. O conceito de alternação tratado por Peter Ludwig Berger, por exemplo, consistiria no ato não totalmente consciente do indivíduo em rememorar, interpretar e reinterpretar seu passado com base numa visão presente, próxima do que os psicólogos chamam de "percepção seletiva", ainda que estes utilizem tal conceituação para o presente. O fenômeno é facilmente observado em contextos de ressocialização ou socialização secundária, como aqueles marcados por mobilidades geográficas (mudança de região ou cultura), sociais (mudança de classe social) ou religiosas (mudança de religião). ${ }^{9}$

Uma dinâmica semelhante à alternação se apresenta na Psicologia e nas Neurociências sob o nome de viés ou filtro, quando distorções e influências inconscientes fazem com que a memória seja resgatada com base em crenças ou juízos do presente. Outras falhas de memória que interferem nos relatos autobiográficos seriam a sugestibilidade e os erros de

\footnotetext{
${ }^{5}$ BOURDIEU, Pierre. A ilusão biográfica. In: BOURDIEU, Pierre. Razões Práticas: Sobre a teoria da ação. Trad.: Mariza Corrêa. $11^{\mathrm{a}}$ ed. Campinas: Papirus. 2014, p. 74-82.

${ }^{6}$ DOSSE, François. O desafio biográfico... Op. cit., p. 208-214.

7 ARFUCH, Leonor. O espaço biográfico: dilemas da subjetividade contemporânea. Trad.: Paloma Vidal. Rio de Janeiro: EdUERJ, 2010, p. 115-116; DOSSE, François. O desafio biográfico... Op. cit., p. 341-343, 408.

${ }^{8}$ BOURDIEU, Pierre. A ilusão biográfica. Op. cit.

${ }^{9}$ BERGER, Peter L. Excurso: Alternação e biografia (Ou: como adquirir um passado pré-fabricado). In: Perspectivas Sociológicas: uma visão humanística. Trad.: Donaldson M. Garschagen. 33a ed. Petrópolis, RJ: Vozes, 2014, p. 65-77; BERGER, Peter L.; LUCKMANN, Thomas. A sociedade como realidade subjetiva. In: A construção social da realidade: tratado de sociologia do conhecimento. Trad.: Floriano de Souza Fernandes. 35a ed. Petrópolis, RJ: Vozes, 2013, p. 167-233.
} 
atribuição. A sugestibilidade consiste na incorporação de informações externas, como quando questionários sugerem ou induzem o interrogado a memórias inverídicas; e os erros de atribuição seriam associações errôneas de momentos, pessoas, objetos e locais a determinadas memórias, resultando nas chamadas "falsas memórias". ${ }^{10}$

Fica claro que nossa discussão diz respeito apenas às memórias declarativas, aquelas que podem ser externadas como discurso, o que nos leva a problemas específicos das memórias coletivamente construídas, compartilhadas e oficializadas. Mesmo nessa seara reconhece-se a condição intrinsecamente reconstrutiva e reinterpretativa da memória, conforme a historiadora Lucy Maynard Salmon pontuava há mais de um século. Entre os motivos elencados pela autora pelos quais a História deve ser reescrita figuram a descoberta e disponibilização de novas fontes documentais de tempos em tempos, ${ }^{11}$ o que nos leva ao objeto específico do presente artigo, também compatível com a postura de Dosse quanto ao posterior preenchimento das lacunas de outrora.

Samuel Wainer foi um jornalista e empresário que se tornou notório no Brasil do século XX, sobretudo pelo seu jornal Ultima Hora e por ter auxiliado na reascensão de Getúlio Vargas. Como é comum às figuras de notoriedade, alguns discursos míticos rondam sua história pública, sacralizando o indivíduo, sua empresa jornalística e alguns feitos particulares nas trajetórias de ambos. Visando desvelar tais discursos, buscamos apresentar a autobiografia Minha Razão de Viver, de Samuel Wainer, a partir de uma perspectiva crítica, confrontando alguns relatos ali contidos com outras fontes bibliográficas e documentais. Foram utilizadas duas edições da supracitada obra, respectivamente de 1988 (editora Record) e 2005 (editora Planeta), ${ }^{12}$ o livro resposta escrito por Rivadávia de Souza em $1989,{ }^{13}$ bem como outros livros, cartas, fotografias e edições de jornais que podem ser consultadas em diferentes acervos. É importante salientar que Minha Razão de Viver se mostra como um documento amplamente utilizado para o estudo histórico e sociológico da imprensa carioca, bem como para a História Política e História da Imprensa no Brasil, figurando na bibliografia de disciplinas e pesquisas acadêmicas nas áreas de Jornalismo, Comunicação, História, Sociologia e Ciência Política. Ambas as edições da biografia serão referenciadas ao longo do texto para facilitar a navegação do leitor, já que a inclusão de fotografias e dados na edição revisada de 2005 resulta numa paginação distinta.

\footnotetext{
10 SCHACTER, Daniel L.; WAGNER, Anthony D. Aprendizado e memória. In: KANDEL, Eric R. et. al. Princípios de Neurociências. Trad.: Ana Lúcia Severo Rodrigues. $5^{a}$ ed. Porto Alegre: AMGH, 2014, p. 1256-1273.

11 SALMON, Lucy Maynard. Why is history rewritten. The North American Review, v. 195, n. 675, p. 225237, fev. 1912. Disponível em: https://www.jstor.org/stable/25119698. Acesso em: 16 set. 2018.

12 WAINER, Samuel. Minha Razão de Viver: memórias de um repórter. $11^{a}$ ed. Rio de Janeiro: Record, 1988; WAINER, Samuel. Minha Razão de Viver: memórias de um repórter. São Paulo: Planeta, 2005.

13 SOUZA, Rivadavia de. Botando os pingos nos is: as inverdades nas memórias de Samuel Wainer. Rio de Janeiro: Record, 1989.
} 


\section{A autobiografia de Samuel: apresentação}

Publicada postumamente, Minha Razão de Viver deriva de três entrevistas de Samuel Wainer gravadas entre janeiro e agosto de 1980. A primeira entrevista foi coordenada e realizada pelo jornalista Sérgio de Souza entre 25 de janeiro e 28 de fevereiro de 1980, resultando em 35 fitas de áudio; a segunda entrevista ocorreu em 25 de junho de 1980 também sob coordenação de Sérgio de Souza, resultando em 4 fitas de áudio; e a terceira entrevista foi coordenada pela jornalista Marta Góes, iniciada em 6 de julho e finalizada em agosto de 1980, resultando em 14 fitas de áudio. ${ }^{14}$ Wainer viria a falecer pouco tempo após a finalização das gravações, em 3 de setembro de 1980. As fitas deram origem a cerca de 1.300 páginas datilografadas, das quais alguns relatos foram selecionados pelo jornalista Augusto Nunes e deram origem à primeira edição do livro, lançado em 1987 pela editora Record. O nome Minha Razão de Viver se aproxima daquele almejado por Wainer, "Uma Razão de Viver". ${ }^{15}$

Estruturalmente a obra se divide em duas partes. A primeira parte (capítulos 1 a 17) traz essencialmente a vida de Wainer antes da fundação do jornal Ultima Hora, compreendendo sua origem e identidade judaica, o início de sua trajetória como jornalista (com ênfase em seu exílio durante o Estado Novo), sua atuação na revista Diretrizes, bem como sua participação como o único brasileiro a cobrir os julgamentos de Nuremberg, para os Diários Associados de Assis Chateaubriand. A segunda parte (capítulos 18 a 36) prioriza a vida de Samuel após a fundação do Ultima Hora, com destaque para a obtenção de apoio político e financeiro para o empreendimento, a Comissão Parlamentar de Inquérito travada por desavenças políticas e ideológicas com Carlos Lacerda, seu exílio de quatro anos após o golpe de 1964, a depredação do jornal em $1^{0}$ de abril de 1964, entre outras memórias. A biografia se encerra com a venda do jornal ao empresário Maurício Nunes de Alencar, em 1972. É importante pontuar que, ao longo da segunda parte, a história de Wainer constantemente se confunde com a história do Ultima Hora, sendo difícil dissociá-las. Dois anos após a publicação de Minha Razão de Viver, o jornalista Rivadávia de Souza publica também pela editora Record o livro Botando os pingos nos is: as inverdades nas memórias de Samuel Wainer, contrapondo alguns pontos narrados por Wainer. Rivadávia foi assessor de imprensa do segundo governo de Getúlio Vargas (1950-1954) e amigo do ex-presidente. Minha Razão de Viver seria relançado em 2005 pela editora Planeta, trazendo uma versão completa e definitiva (segundo a introdução de Augusto Nunes), com a inclusão de fotografias, documentos e algumas revelações. ${ }^{16}$

\footnotetext{
${ }^{14}$ WAINER, Samuel. Minha Razão de... Op. cit., 1988, p. 11; WAINER, Samuel. Minha Razão de... Op. cit., 2005, p. 13.

${ }^{15}$ ROUCHOU, Joëlle. Samuel: duas vozes de Wainer. $2^{a}$ ed. Rio de Janeiro: UniverCidade, 2004, p. 146.

${ }^{16}$ WAINER, Samuel. Minha Razão de... Op. cit., 2005, p. 5.
} 
Entre as categorias propostas por Dosse, ${ }^{17}$ Minha Razão de Viver se apresenta majoritariamente como uma biografia modal, por trazer Samuel Wainer não como um sujeito exemplar do seu tempo, mas ainda assim uma figura digna de ser rememorada. Nesta modalidade de narrativa biográfica, o singular - Samuel Wainer - é tomado como caso representativo do coletivo, ${ }^{18}$ resgatando, pelo percurso de uma narrativa individual, o contexto e os reflexos de uma época e de determinadas categorias sociais. A obra não deixa de apresentar certos traços heroicos, como a ascensão do garoto judeu pobre que ingressaria numa elite oligárquica e traria ao grande público um jornalismo que marcaria época. A negligência da esfera pessoal reduz a pluralidade das identidades possíveis, distanciando esta obra de uma biografia hermenêutica. Como afirmamos acima, as categorias não são estanques nem do ponto de vista cronológico, nem na tessitura do texto.

As 1.300 páginas datilografadas foram analisadas por Joëlle Rouchou em sua pesquisa de mestrado Samuel: as duas vozes de Wainer (defendida em 1996 e posteriormente publicada como livro). Rouchou aborda Wainer a partir de sua dupla identidade e duplo pertencimento, como judeu (vida privada) e jornalista (vida pública), se apoiando tanto em Minha Razão de Viver quanto nas páginas datilografadas que deram origem à obra, denominadas pela pesquisadora como "material bruto". ${ }^{19}$ Para o presente artigo utilizamos o livro Samuel: duas vozes de Wainer, de 2004. Se Minha Razão de Viver se distancia de uma biografia hermenêutica pela redução das identidades possíveis numa sociedade modernocontemporânea, a obra de Rouchou busca resgatar a complexidade contida no "material bruto", mas mantém a assimetria de apenas duas categorias - jornalista e judeu - sobre outras tantas possíveis.

Adiante, episódios e informações pontuais trazidas por Wainer serão confrontadas com outros livros e documentos, evidenciando ao leitor alguns equívocos inerentes ao resgate e à construção da memória autobiográfica ou à sua oficialização enquanto narrativa.

\section{Para além da autobiografia: uma análise crítica}

Em nível introdutório da problemática podemos citar as origens de Samuel Wainer. O verbete disponível no Centro de Pesquisa e Documentação de História Contemporânea no Brasil (CPDOC) apresenta como local de nascimento a cidade de São Paulo, em 16 de janeiro

\footnotetext{
17 DOSSE, François. O desafio biográfico... Op. cit.

${ }^{18}$ Este é caso da biografia do cavaleiro Guilherme Marechal, realizada por Georges Duby. O exemplo é oferecido por Dosse. Na biografia, o medievalista francês afirmou: "O meu propósito é simplesmente o de esclarecer o que ainda se conhece pouco, recolhendo nesse testemunho, cujo excepcional valor já apontei, o que ele nos conta da cultura dos cavaleiros". DUBY, Georges. Guilherme Marechal ou o melhor cavaleiro do mundo. Trad.: Renato Janine Ribeiro. Rio de Janeiro: Graal, 1987, p. 54. Anos depois, o mesmo Duby recuperaria a experiência em sua biografia intelectual, $A$ História continua: "O verdadeiro tema do livro não é Guilherme, mas a cavalaria, seu ideal, os valores que ela afirmava respeitar". DUBY, Georges. A História continua. Trad.: Clóvis Marques. Rio de Janeiro: Zahar, 1993, p. 139.
}

${ }^{19}$ ROUCHOU, Joëlle. Samuel... Op. cit., p. 17-18. 
de $1912,{ }^{20}$ data que coincide com a primeira versão da autobiografia, mas que seria retificada nas edições posteriores a 2005. A introdução de Augusto Nunes e a apresentação de Pinky Wainer nas edições mais recentes trazem a cidade de Edenitz (na Bessarábia, atual República Moldova) como local de nascimento e 19 de dezembro de 1910 como data de nascimento. ${ }^{21} \mathrm{~A}$ omissão de sua nacionalidade na primeira edição do livro exemplifica a problemática trazida por Pierre Bourdieu, de que a narrativa autobiográfica deve atender a determinado mercado de bens simbólicos, tendo em vista que a Constituição de 1946 impedia que estrangeiros fossem donos de empresas jornalísticas e, consequentemente, que Wainer fundasse o jornal Ultima Hora em 1951. Na introdução da versão definitiva, Augusto Nunes aponta que antes de falecer Samuel pediu a sua filha, Pinky Wainer, que tais informações só fossem apresentadas após 25 anos de sua morte, explicando o hiato que sondou sua história por tanto tempo. ${ }^{22}$

Ainda que este exemplo figure como intencional, partindo da deliberação de Wainer e o compromisso de sua filha em reeditar o livro de memórias em momento oportuno, tal situação não deixa de trazer problemas ao pesquisador que busca por dados factuais, tendo em vista que trabalhos acadêmicos e até mesmo guias de acervos e arquivos públicos atribuem datas equivocadas e díspares, havendo até mesclas entre as supracitadas. A própria reedição da obra traz uma inconsistência entre a apresentação de Augusto Nunes e a legenda de uma fotografia que retrata Wainer e sua família partindo do porto italiano de Gênova ao Brasil. Enquanto Augusto atesta que Wainer nasceu na Bessarábia e chegou ao Brasil com 2 anos de idade, ${ }^{23}$ a legenda da fotografia indica que Samuel e sua família partiram de Gênova ao Brasil quando ele tinha 6 anos de idade. ${ }^{24}$

Já no Brasil e ainda adolescente, Wainer iniciou sua carreira jornalística como colaborador da seção "Diário Israelita" em $1933,{ }^{25}$ no Diário de Notícias, ainda como estudante de Farmácia, curso que não viria a concluir. ${ }^{26} \mathrm{Em} \mathrm{1938,} \mathrm{a} \mathrm{convite} \mathrm{de} \mathrm{Antônio} \mathrm{José} \mathrm{de} \mathrm{Azevedo}$ Amaral, funda com este a revista mensal Diretrizes (transformada em semanário 3 anos mais tarde), com o objetivo de relatar o cenário político do país naquele momento e fazer oposição ao regime varguista, fato que resultaria na suspensão do suprimento de papel da revista em 1944. Devido a este episódio Wainer solicita asilo à embaixada do México no Brasil como medida cautelar e segue para o exílio, passando pelo Uruguai, Argentina (onde foi correspondente do $O$ Globo e colaborou para a imprensa norte-americana), Chile, Estados

${ }^{20}$ LEMOS, Renato. Samuel Wainer. (Verbete). In: Dicionário Histórico-Biográfico Brasileiro-DHBB. Rio de Janeiro: CPDOC/FGV, [s.d.]. Disponível em: http://www.fgv.br/cpdoc/acervo/dicionarios/verbetebiografico/wainer-samuel. Acesso em: 7 nov. 2018.

${ }^{21}$ WAINER, Samuel. Minha Razão de... Op. cit., 2005, p. 5.

${ }^{22}$ Ibidem, p. 6.

${ }^{23}$ Idem.

${ }^{24}$ Legenda na íntegra: "A prova definitiva: no porto italiano de Gênova, Samuel, aos seis anos, parte com os pais e irmãos para o Brasil". Ibidem, p. 15.

25 Diário Israelita. Diário de Notícias, Rio de Janeiro, 20 jun. 1933, p. 3. Disponível em: http://memoria.bn.br/docreader/093718_01/15081. Acesso em: 7 nov. 2018.

${ }^{26}$ WAINER, Samuel. Minha Razão de... Op. cit., 1988, p. 45; WAINER, Samuel. Minha Razão de... Op. cit., 2005, p. 55. 
Unidos e México, posteriormente seguindo para a Europa, onde atuou como correspondente de Diretrizes (sem credenciais, segundo sua obra) no julgamento de Nuremberg. ${ }^{27}$ De volta ao Brasil em 1947, Wainer vende Diretrizes e passa a trabalhar como chefe de redação em $O$ Jornal, da rede de jornais de Assis Chateaubriand, Diários Associados. ${ }^{28}$

Em 1949 Samuel Wainer entrevistaria Getúlio Vargas em sua fazenda no Rio Grande do Sul após, segundo consta em seu livro de memórias, ter solicitado ao piloto que desviasse a rota do bimotor fretado por Chateaubriand para que fizesse uma reportagem sobre a cultura do trigo na região. De volta a São Paulo, Wainer deixa um exemplar do texto na mesa de Chateaubriand. Segundo sua obra a entrevista rendeu uma tiragem de 180 mil exemplares, demonstrando uma cifra considerável se comparada com a vendagem média do jornal, de aproximadamente 9 mil exemplares. ${ }^{29}$ Entretanto, a verificação da tiragem é inconclusiva, já que na época não havia órgãos para a checagem de circulação com baixa margem de erro, como o IVC (Instituto de Verificação de Circulação), criado em $1961 .^{30}$

Notam-se algumas inconsistências quanto à entrevista de Vargas, publicada em 3 de março de 1949. Segundo Wainer, "[n]a mesma quinta-feira, o jornal soltou a manchete: 'eu voltarei como líder de massas'. No alto, aparecia um selo que se tornaria a marca registrada das minhas entrevistas com Getúlio: 'De Vargas para Wainer'". ${ }^{31}$ Entretanto, a manchete presente na edição com a referida entrevista traz os seguintes dizeres "O DEBATE DA SUCESSÃO PRESIDENCIAL NÃO PODERÁ SER MAIS CONTIDO", e abaixo "Reportagem de Samuel Wainer; Exclusividade dos Diários Associados". ${ }^{32}$ O único momento em que a reportagem traz a expressão "líder de massas" encontra-se na segunda parte da entrevista, reproduzida na página 6 da mesma edição, mas de forma sutil e distinta da versão evocada por Wainer, quando Vargas concorda com a asserção do repórter de que ele seria um líder de massas. $^{33}$ Lira Neto também sinaliza as inconsistências entre a narrativa de Wainer e a entrevista efetivamente publicada em Getúlio: Da volta pela consagração popular ao suicídio

\footnotetext{
27 WAINER, Samuel. Minha Razão de... Op. cit., 1988, p. 67-88; WAINER, Samuel. Minha Razão de... Op. cit., 2005, p. 82-107.

28 LAURENZA, Ana Maria de Abreu. Lacerda $x$ Wainer: O Corvo e o Bessarabiano. $2^{a}$ ed. São Paulo: Senac, 1998, p. 48.

${ }^{29}$ WAINER, Samuel. Minha Razão de... Op. cit., 1988, p. 19-25; WAINER, Samuel. Minha Razão de... Op. cit., 2005, p. 24-31.

30 LAURENZA, Ana Maria de Abreu. Lacerda $x$ Wainer... Op. cit., p. 53.

31 WAINER, Samuel. Minha Razão de... Op. cit., 1988, p. 25; WAINER, Samuel. Minha Razão de... Op. cit., 2005, p. 31.

32 WAINER, Samuel. O debate da sucessão presidencial não poderá ser mais contido. O Jornal, Rio de Janeiro, 3 mar. 1949. p. 1. Disponível em: http://memoria.bn.br/DocReader/110523_04/47850. Acesso em: 18 nov. 2018. (Material protegido por direitos autorais).

33 Ibidem, p. 6. (Conclusão da primeira página). Disponível em: http://memoria.bn.br/DocReader/110523_04/47855. Acesso em: 18 nov. 2018. (Material protegido por direitos autorais).
} 
(1945-1954), ${ }^{34}$ assim como Luís Ricardo Araujo da Costa, em Bota o retrato do velho Getúlio outra vez: a campanha presidencial de 1950 na imprensa do Rio de Janeiro. ${ }^{35}$

Em outubro de 1953 Assis Chateaubriand publicaria uma matéria intitulada "UMA HISTORIA MAL CONTADA" no periódico O Jornal, trazendo críticas ao pronunciamento de Luthero Vargas na Câmara dos Deputados, quando alegou que Samuel Wainer pôs em risco seu emprego nos Diários Associados ao apoiar a candidatura de Getúlio. Chateaubriand acusa Luthero de ingrato e desmemoriado pela alegação e por creditar o apoio e a promoção da candidatura desde 1947 somente a Samuel Wainer. ${ }^{36}$ Fernando Morais, autor da biografia de Assis Chateaubriand (Chatô, o rei do Brasil), atenta que Carlos Castelo Branco, Austregésilo de Athayde e Freddy Chateaubriand, que trabalharam com Wainer em $O$ Jornal, contestam a versão de que o repórter havia se encontrado com Getúlio sem compromisso, e que Chateaubriand ordenou sua ida ao Sul já com o propósito de entrevistar o ex-chefe de Estado brasileiro. ${ }^{37}$ Ainda sobre este episódio, cartas trocadas entre Alzira Vargas e seu pai Getúlio Vargas apontam que a entrevista fora premeditada, divergindo da versão de Wainer. Numa carta endereçada a Vargas em 18 de fevereiro de 1949 Alzira orienta o pai sobre a visita de um emissário credenciado da União Democrática Nacional (UDN), sem mencionar nomes. ${ }^{38}$ Em resposta a Alzira, em 22 de fevereiro de 1949, Getúlio concorda em receber o emissário, fazendo algumas observações. ${ }^{39}$ Em 28 de fevereiro Getúlio novamente escreve para sua filha, alertando sobre a visita de Wainer:

Tive a visita inesperada do jornalista Samuel Wainer, que veio indagar sobre o apoio à candidatura de Brigadeiro, que estava incendiando, e também aproveitou para pedir-me perdão das safadezas que tinha feito contra mim. Perdoei e respondi que não havia recebido nenhum emissário, nem assumido qualquer compromisso até o presente. $\mathrm{E}$ foi só. ${ }^{40}$

Em março Alzira confirmaria ao seu pai que "[o] [emissário] da UDN foi o seu Wainer, que, aproveitando nossa ausência do Rio antes do carnaval, saiu sem aviso". ${ }^{41} \mathrm{~A}$ identificação de Wainer como emissário da UDN também pode ser depreendida de outra carta de Alzira, em

\footnotetext{
34 NETO, Lira. Getúlio: Da volta pela consagração popular ao suicídio (1945-1954). São Paulo: Companhia das Letras, 2014, p. 159-160.

${ }^{35}$ COSTA, Luís Ricardo Araujo da. Bota o retrato do velho Getúlio outra vez: a campanha presidencial de 1950 na imprensa do Rio de Janeiro. 2014. Dissertação (Mestrado em História) - Departamento de História, Instituto de Ciências Humanas e Filosofia, Universidade Federal Fluminense, Niterói (RJ), p. 2021.

36 CHATEAUBRIAND, Assis. Uma história mal contada. O Jornal, Rio de Janeiro, 4 out. 1953, p. 4. Disponível em: http://memoria.bn.br/docreader/110523_05/24154. Acesso em: 14 nov. 2018. (Material protegido por direitos autorais).

37 MORAIS, Fernando. Chatô: o rei do Brasil. São Paulo: Companhia das Letras, 1994, p. 495.

38 NOVAES E CRUZ, Adelina; MOREIRA, Regina da Luz (orgs.). Volta ao poder: a correspondência entre Getúlio e a filha Alzira. Vol. 2: 1949 a 1950. Rio de Janeiro: FGV Ed.: Ouro sobre Azul, 2018, p. 37.

${ }^{39}$ Ibidem, p. 40.

${ }^{40}$ Ibidem, p. 42.

${ }^{41}$ Ibidem, p. 55.
} 
9 de março de $1949 .{ }^{42}$ Lira Neto também narra o acontecimento com base nas cartas de Getúlio e sua filha, observando que Minha Razão de Viver não trata a ida de um repórter dos Diários Associados a São Borja como "um plano previamente traçado no Rio de Janeiro, com a devida combinação entre representantes da UDN e a filha do ex-presidente". ${ }^{43} \mathrm{O}$ autor também levanta a hipótese de que o jornalista talvez sequer soubesse disto. Desta forma, as cartas trocadas entre Alzira e Getúlio e as edições de O Jornal analisadas divergem da narrativa contida em Minha Razão de Viver, oferecendo possibilidades de confrontar e contestar tal relato. Supondo a ciência de Wainer em participar de um projeto político mais amplo, a reordenação dos eventos em sua narrativa pode decorrer de diversos fatores, que compreendem desde a alternação (considerando-se o longo hiato entre a entrevista com Getúlio e a gravação de seu relato), a impossibilidade de Wainer verificar e confirmar tais informações (tendo em vista sua morte pouco após a finalização das gravações) e a formalização de uma narrativa que atendesse às expectativas específicas de um público almejado (a imagem do jornalista que está no lugar certo e na hora certa para o furo jornalístico).

Quanto à repercussão da entrevista, Wainer relata que Benjamin Vargas (irmão do exchefe de Estado) Ihe transmitiu o agradecimento de Getúlio, que estaria entusiasmado com a repercussão da notícia. Getúlio teria creditado a Samuel sua redescoberta pelo povo, vindo a ser "procurado por dezenas de políticos e que cartas do Brasil inteiro choviam sobre São Borja". ${ }^{44}$ Num trecho das gravações apresentado por Joëlle Rouchou, Samuel afirma que "Getúlio não dava entrevistas a outro jornal, não confiava em outro jornalista, alguns até íntimos". ${ }^{45}$ Entretanto, de acordo com Rivadávia de Souza, "a romaria de políticos, amigos, seguidores e jornalistas nunca deixou de ser incessante na Tebaida da fronteira gaúcha", ${ }^{46}$ e Getúlio teria cedido uma entrevista para Edmar Morel, dos Diários Associados, logo após sua deposição em 1945. Em nível de exemplo, uma busca no repositório digital da Biblioteca Nacional traz entre seus resultados uma entrevista de Getúlio Vargas ao matutino Diário de Notícias em novembro de 1947, onde trata das eleições no estado de São Paulo. ${ }^{47}$

Rivadávia rememora ter sido redator da Agência Nacional durante o Estado Novo, cobrindo grande parte das viagens do ex-chefe de Estado. Ao fim do governo passou a integrar a redação do jornal gaúcho Correio do Povo, onde acompanharia (com o aval de Breno Caldas, diretor do periódico) todos os políticos e figuras públicas que fossem ao encontro de Getúlio na

\footnotetext{
42 NOVAES E CRUZ, Adelina; MOREIRA, Regina da Luz (orgs.). Volta ao poder... Op. cit., p. 45.

43 NETO, Lira. Getúlio... Op. cit., p. 161.

${ }^{44}$ WAINER, Samuel. Minha Razão de... Op. cit., 1988, p. 25-26; WAINER, Samuel. Minha Razão de... Op. cit., 2005, p. 31-32.

45 WAINER, Samuel. Apud: ROUCHOU, Joëlle. Samuel... Op. cit., p. 57.

46 SOUZA, Rivadavia de. Botando os pingos... Op. cit., p. 25.

47 Reação das forças morais de São Paulo em favor da Democracia. Diário de Notícias, Rio de Janeiro, 14 nov. 1947, p. 3. Disponível em http://memoria.bn.br/docreader/093718_02/35910. Acesso em: 30 nov. 2018.
} 
fazenda de Itu. ${ }^{48}$ Rivadávia alerta que o suposto ostracismo de Getúlio e o resgate feito por Wainer não possuem fundamentação, visto que Hugo Borghi havia se encontrado com o exestadista em 1945 e solicitado uma carta de apoio à candidatura presidencial de Eurico Gaspar Dutra pelo Partido Social Democrático. A carta foi lida durante um comício para milhares de pessoas. ${ }^{49}$

Outros equívocos também são apontados ao longo de Botando os pingos nos is: as inverdades nas memórias de Samuel Wainer, alguns de difícil verificação e comparação com outras fontes documentais (como, por exemplo, o tom enérgico de Bluma Wainer para com seu esposo Samuel). Entre equívocos cuja confrontação com outras fontes pôde ser realizada, destacamos três ocorrências: as fronteiras de São Borja; a viagem de João Goulart à China durante a renúncia de Jânio Quadros; e as viagens internacionais de Getúlio Vargas na presidência.

Segundo Wainer, o município gaúcho de São Borja faria fronteira com o Uruguai. ${ }^{50}$ Rivadávia contesta o "sacrilégio geográfico" e aponta que o município "[f]ica em frente a São Tomé, na Argentina. Mais abaixo, situa-se o município de Itaqui, fronteiro a Alvear, também na Argentina, e finalmente, [...] Uruguaiana defronte a Passo de los Libres, encarando o território argentino", ${ }^{51}$ discorrendo também sobre a história, formação étnica e origem do nome do município. ${ }^{52}$

Quanto à crise da renúncia de Jânio Quadros (consumada em 25 de agosto de 1961), Wainer teria recebido pela madrugada uma ligação de João Goulart, que se encontrava em Paris, entre escalas, questionando Samuel se deveria ou não regressar ao Brasil. ${ }^{53}$ Rivadávia contra-argumenta que João Goulart se encontrava em Xangai, prestes a regressar ao Brasil, quando tomou conhecimento da renúncia de Jânio e passou a receber diversos telefonemas dos amigos mais próximos, sendo implausível que o político tenha telefonado para Wainer. ${ }^{54}$ Com base na edição única de 26 de agosto de 1961 do jornal Ultima Hora, "[a]té o momento de encerrar esta edição, reinava enorme confusão em torno da partida do Sr. João Goulart, de Singapura para Brasília" (deve-se salientar que o fechamento das edições normalmente ocorria entre o fim da noite e início de madrugada, seguindo para a impressão). ${ }^{55}$ No mesmo dia o Jornal do Brasil noticiaria algo semelhante, adicionando que João Goulart teve conhecimento

\footnotetext{
${ }^{48}$ SOUZA, Rivadavia de. Botando os pingos... Op. cit., p. 26.

${ }^{49}$ Idem; VARGAS, Getúlio. [Carta] 25 nov. 1945, [s.I.]. 1 f. Carta de apoio a candidatura de Eurico Gaspar Dutra. Disponível em: http://memorialdademocracia.com.br/card/ele-disse-votai-emdutra/docset/995. Acesso em: 9 nov. 2018.

50 WAINER, Samuel. Minha Razão de... Op. cit., 1988, p. 19; WAINER, Samuel. Minha Razão de... Op. cit., 2005, p. 25.

${ }^{51}$ SOUZA, Rivadavia de. Botando os pingos... Op. cit., p. 31-32.

52 Ibidem, p. 33.

53 WAINER, Samuel. Minha Razão de... Op. cit., 1988, p. 233-234; WAINER, Samuel. Minha Razão de... Op. cit., 2005, p. 301-302.

${ }^{54}$ SOUZA, Rivadavia de. Botando os pingos... Op. cit., p. 77-79.

${ }^{55}$ Incrível confusão em torno de Jango. Ultima Hora, Rio de Janeiro, 26 ago. 1961, p. 1. Disponível em: http://memoria.bn.br/DocReader/386030/70636. Acesso em: 9 nov. 2018.
} 
da renúncia em Singapura, recém-chegado de Hong Kong, durante a madrugada. ${ }^{56}$ Os jornais supracitados sinalizam possíveis equívocos tanto nas memórias de Wainer quanto nas de Rivadávia.

Ao descrever a personalidade e as inclinações nacionalistas de Getúlio em Minha Razão de Viver, Wainer aponta que tais tendências "foram reforçadas pelo fato de que passou praticamente toda a sua vida sem viajar ao exterior - com exceção da Argentina, que visitou quando presidente, ele não conheceu nenhum outro país". ${ }^{57}$ Rivadávia aponta este trecho lamentando o "desconhecimento de Samuel sobre os passos do seu amigo, com quem alardeia ter mantido profunda intimidade", ${ }^{58}$ e exemplifica este desconhecimento citando as visitas de Getúlio ao Uruguai e ao Paraguai. Uma consulta ao catálogo iconográfico do Centro de Fotografía de Montevideo (CDF), presente em seu sítio oficial, revela uma fotografia de Getúlio Vargas junto ao presidente uruguaio Gabriel Terra e demais convidados para uma festa de recepção em sua homenagem, confirmando sua visita ao país em 1935 (Figura 1). Já a viagem de Getúlio ao Paraguai pode ser confirmada através do acervo audiovisual do CPDOC, onde encontramos uma fotografia de Getúlio na cidade de Assunção em 1941, junto a Higino Morinigo, Luiz Argaña, Otávio Figueiredo de Medeiros e Aristides Guillem. ${ }^{59}$

\footnotetext{
56 País em calma espera chegada de João Goulart. Jornal do Brasil, Rio de Janeiro, 26 ago. 1961, p. 1. Disponível em: http://memoria.bn.br/DocReader/030015_08/21358. Acesso em: 9 nov. 2018. (Material protegido por direitos autorais).

57 WAINER, Samuel. Minha Razão de... Op. cit., 1988, p. 124; WAINER, Samuel. Minha Razão de... Op. cit., 2005, p. 152.

${ }^{58}$ SOUZA, Rivadavia de. Botando os pingos... Op. cit., p. 126.

59 Centro de Pesquisa e Documentação de História Contemporânea - Fundação Getúlio Vargas (CPDOC/FGV). AVAP foto 089: Alzira Vargas do Amaral Peixoto, Getúlio Vargas e outros em viagens e eventos sociais. Disponível em: http://www.fgv.br/cpdoc/acervo/arquivopessoal/AVAP/audiovisual/alzira-vargas-do-amaral-peixoto-getulio-vargas-e-outros-em-viagens-eeventos-sociais. Acesso em: 28 nov. 2018. Ver, também: CPDOC/FGV. GV foto 104: Getúlio Vargas e outros durante visita ao Paraguai. Disponível em: http://www.fgv.br/cpdoc/acervo/arquivopessoal/GV/audiovisual/getulio-vargas-e-outros-durante-visita-ao-paraguai. Acesso em: 28 nov. 2018.
} 
Figura 1 - Getúlio Vargas em visita ao Uruguai

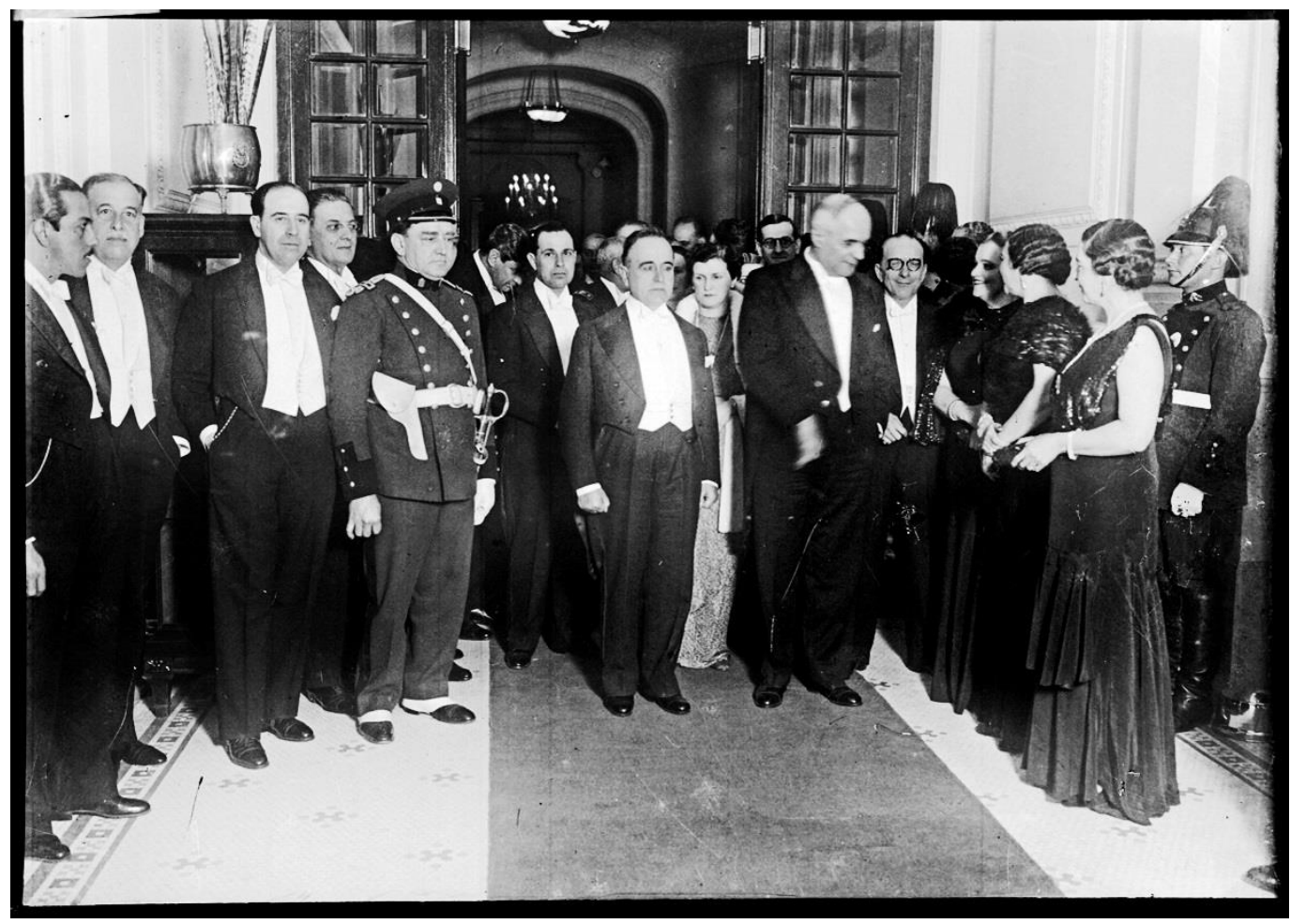

Fonte: Centro de Fotografía de Montevideo. 0636FMHC. 9x12cm. p\&b. Disponível em: http://cdf.montevideo.gub.uy/catalogo/foto/0636fmhc. Acesso em: 28 nov. 2018.

Enquanto algumas informações de Minha Razão de Viver podem ser confrontadas e falseadas com outras fontes documentais, outras se sustentam. Wainer é frequentemente chamado de "Profeta" na literatura e Minha Razão de Viver é a fonte preferencial de tal informação, mas uma carta de Alzira Vargas a Samuel Wainer Filho também nos apresenta este apelido em abril de $1984,{ }^{60}$ sendo anterior à publicação da autobiografia e posterior às entrevistas gravadas que originaram o "material bruto" analisado por Rouchou. Entretanto, divergências podem ser pontuadas quanto à gênese do apelido. Para Wainer, Getúlio estaria aludindo ao fato dele ser "o primeiro repórter a prever seu retorno, e anunciá-lo nas páginas de um jornal", ${ }^{61}$ mas sem descartar a possível influência do nome "Samuel" sobre a escolha. Rivadávia contrapõe a narrativa de Wainer alegando ser hábito de Getúlio atribuir apelidos às pessoas próximas, e que Wainer estaria ignorando as origens bíblicas de seu nome. ${ }^{62}$ Samuel pode ser acusado de atribuir peso excessivo a uma suposta "profecia realizada", mas o simples fato de não discorrer sobre a origem de seu nome é algo bem distinto de ignorar as possíveis

\footnotetext{
60 PEIXOTO, Alzira Vargas do Amaral. [Carta] abr. 1984, Rio de Janeiro. 1f. Carta de Alzira Vargas do Amaral Peixoto a Samuel Wainer Filho. Disponível em: http://docvirt.com/docreader.net/FGV_AVAP_VPR/744. Acesso em: 5 dez. 2018.

61 WAINER, Samuel. Minha Razão de... Op. cit., 1988, p. 17; WAINER, Samuel. Minha Razão de... Op. cit., 2005, p. 21.

${ }^{62}$ SOUZA, Rivadavia de. Botando os pingos... Op. cit., p. 99-101.
} 
influências sobre o apelido. A pouca preocupação em esmiuçar narrativas judaico-cristãs apenas reforça hipóteses quanto à adesão de Wainer à tradição judaica, já que seria desnecessário explicar algo de conhecimento amplo, supostamente presente no domínio conceitual comum de seus interlocutores.

Minha Razão de Viver carrega consigo reflexos sócio-históricos de um fazer jornalístico específico, e a "mítica" tratada pela comunicóloga Marialva Barbosa acerca do jornal Ultima Hora nos permite abordar estes reflexos de maneira exemplar. Tal mítica se constrói e se cristaliza nos discursos e memórias de jornalistas que atuaram no jornal, incluindo Samuel Wainer. Segundo Marialva, a construção coletiva de um ideário específico possibilitou a reprodução e perenização de uma imagem quase sacralizada do Ultima Hora e da profissão de jornalista, enfatizando as agruras e êxitos do meio:

A imagem de sacerdócio ligada à atividade profissional faz com que destaquem sacrifícios inerentes à profissão e ao cotidiano duro, com horários incertos e parcos recursos materiais. Nas suas memórias, os jornalistas transmitem ao futuro um legado de experiências adquirido no dia-a-dia da profissão, construindo-se como espécies de testemunhas privilegiadas de uma época. Ao fazê-lo, constroem uma imagem preponderante do seu eu - sujeito de sua própria descrição -, caracterizando-se de maneira peculiar e transmitindo essa idealização como memória do grupo. ${ }^{63}$

Entre diversos elementos que compõem e resultam desta mítica, a construção de repórteres como "testemunhas privilegiadas de uma época" merece especial destaque. Tendo em vista a posição social destes indivíduos e de suas empresas, as concordâncias tácitas entre eles e as dinâmicas de reprodução e circulação dos discursos, tal particularidade pode fazer com que as narrativas pessoais e únicas de um profissional se estabeleçam na memória do grupo, migrem para outros grupos e passem a compor (ou construir) determinados "fatos históricos". A afirmação de Wainer em Minha Razão de Viver acerca da entrevista com Getúlio ("Eu pressentia que estávamos documentando um capítulo crucial da História do Brasil") ilustra o fenômeno descrito, ${ }^{64}$ e sua versão se oficializa, por exemplo, na obra de Boris Fausto, quando o historiador replica o discurso: "mas o repórter resolveu tentar uma cartada que mudaria sua vida: entrevistar Getúlio", incluindo também a suposta fala de Getúlio ("Sim, eu voltarei, não como líder político, mas líder das massas"). ${ }^{65}$

Na contramão dos discursos sacralizados e sacralizantes da profissão e do Ultima Hora, o jornalista Moacir Werneck de Castro alerta que Minha Razão de Viver deve ser lida com cautela, e que Samuel Wainer entregou-se a um monólogo incessante ao gravador rendendo mais de mil páginas datilografadas, das quais Augusto Nunes selecionou aproximadamente

\footnotetext{
${ }^{63}$ BARBOSA, Marialva. História Cultural da Imprensa: Brasil, 1900-2000. 2a ed. Rio de Janeiro: Mauad X, 2007, p. 101.

64 WAINER, Samuel. Minha Razão de... Op. cit., 1988, p. 28; WAINER, Samuel. Minha Razão de... Op. cit., 2005, p. 34.

65 FAUSTO, Boris. Getúlio Vargas: o poder e o sorriso. São Paulo: Companhia das Letras, 2006, p. 162163.
} 
400 para o livro, priorizando os aspectos que considerava mais importantes. ${ }^{66} \mathrm{O}$ livro, produto desta seleção, contempla tanto trechos cronologicamente ordenados quanto quebras na ordenação temporal. Como exemplo, o texto se inicia com Wainer descrevendo uma reunião com o candidato vencedor das eleições presidenciais de 1950 (Getúlio Vargas) e João Goulart num quarto da fazenda de São Pedro, do embaixador Batista Luzardo. Alguns desvios de linearidade talvez se devam ao fato de que não foi Wainer quem separou o material para sua autobiografia, mas Augusto Nunes, uma hipótese que é reforçada pelas observações de Joëlle Rouchou quanto ao início da narrativa constante no "material bruto", quando Wainer busca apresentar as origens da família a seus filhos através de metáforas bíblicas. ${ }^{67}$

Pode-se inferir que esta obra não é estritamente e necessariamente uma autobiografia, mas também uma biografia, tendo em vista resultar de entrevistas conduzidas por Sérgio de Souza e Marta Góes, e posterior seleção, edição e transcrição por Augusto Nunes: uma produção coletiva. Ainda que resulte de entrevistas, Minha Razão de Viver restringe a estrutura dialógica de perguntas e respostas aos bastidores de sua produção, sendo breves os comentários sobre eventuais perguntas na bibliografia consultada. ${ }^{68} \mathrm{~A}$ apresentação final como narrativa contínua reforça o efeito de espontaneidade e autenticidade tratado por Leonor Arfuch através da eliminação de referências às interlocuções previamente planejadas, ${ }^{69}$ escondendo o papel ativo, performativo e mediador dos entrevistadores. Embora a trajetória de Samuel e a de seu jornal sejam de difícil dissociação, o enfoque na seleção de eventos feita por Augusto Nunes coloca em voga a "razão de viver" do jornalista, reforçando uma espécie de real sentido - e objetivo - de Wainer, conforme aponta Bourdieu acerca da ordenação teleológica das narrativas biográficas. Enquanto resultado de um trabalho coletivo levado adiante por jornalistas, talvez a aceitação tácita do jornalismo enquanto telos tenha sido uma consequência mais ou menos previsível. Não obstante, tal impressão se reforça pela apresentação de Augusto Nunes, que trata Minha Razão de Viver como "a melhor reportagem concebida pelo próprio Samuel Wainer."

A pesquisa de Joëlle Rouchou sobre as 1.300 páginas datilografadas menciona também Moacir Werneck de Castro como um colaborador fundamental para que Samuel pudesse organizar suas memórias, ao recordar datas e referências que estavam lacunares e nebulosas para seu amigo e antigo colega de profissão. Segundo Rouchou, "[o] primeiro relato que Werneck the enviou tinha 120 linhas datilografadas em espaço um, num tipo bem miúdo, contendo uma cronologia abrangente, com um resumo dos tópicos mais importantes de

66 CASTRO, Moacir Werneck de. Samuel e Lacerda ficaram fascinados um pelo outro. In: BARROS, Antonio Theodoro de Magalhães et al. A Última Hora de Samuel Nos Tempos de Wainer. Rio de Janeiro: ABI-Copim, 1993, p. 79-85.

${ }^{67}$ ROUCHOU, Joëlle. Samuel... Op. cit., p. 26-27.

${ }^{68}$ Ibidem, p. 94; WAINER, Samuel. Minha Razão de... Op. cit., 2005, p. 6.

${ }^{69}$ ARFUCH, Leonor. O espaço biográfico... Op. cit., p. 167.

70 WAINER, Samuel. Minha Razão de... Op. cit., 1988, orelha do livro; WAINER, Samuel. Minha Razão de... Op. cit., 2005, p. 8. 
Samuel", ${ }^{71}$ e sem este rumo a autobiografia não existiria. Pinky Wainer, filha de Samuel, relata à pesquisadora que seu pai solicitou interlocutores para rememorar sua trajetória, alegando que sem este recurso não conseguiria reavivar suas lembranças. Mesmo com tais recursos e estratégias adotadas, Rouchou descreve o relato autobiográfico de Samuel em sua totalidade como fragmentário, ao contar sobre alguns episódios de maneira desordenada e por vezes repetitiva. Para a pesquisadora isto pode ter decorrido dos intervalos entre as gravações, que levaram várias semanas para serem concluídas. ${ }^{72}$

Ao trazer alguns relatos do jornalista, Samuel: duas vozes de Wainer replica certas inconsistências anteriormente abordadas neste artigo, como o episódio da reportagem do trigo no Sul, que teria resultado na entrevista "inesperada" com Getúlio; o teor e a repercussão desta em O Jornal; e que Getúlio não daria entrevistas a outros jornais por não confiar em outros jornalistas. No entanto, é importante salientar que o trabalho de Rouchou possui um propósito distinto do nosso, e buscou analisar a personalidade de Samuel Wainer a partir de seu duplo pertencimento e sua dupla identidade, atendo-se ao resgate de suas memórias ora enquanto elementos emanadores de tradições judaicas, ora enquanto elementos inerentes à profissão de jornalista e sua vida pública, sobretudo com a fundação do jornal Ultima Hora. Mesmo com o foco díspar comparado ao presente trabalho, a autora tece críticas a Wainer, como quanto ao rancor e ódio que este teria por Assis Chateaubriand, seu antigo chefe:

O espaço dedicado a Chateaubriand é revelador. Talvez como um espelho que Wainer não quisesse olhar. Ele aponta todos os defeitos do empresário como sendo tudo aquilo que ele execrasse. Mas qual o proprietário de jornal, ou de qualquer outro órgão de comunicação, que não trabalha para atender a seus próprios interesses? Samuel não teria usado também seus veículos para divulgar suas ideias? Será que ele usou jornais e revistas para conquistar - numa notinha em coluna social que fosse, por exemplo - alguma moça pela qual estivesse encantado? Samuel reconhece que errou, que vendeu a alma ao diabo para defender seu jornal. Mas será apenas o jornal, tudo realmente pelo jornal? ${ }^{73}$

Rouchou menciona a obra Botando os pingos nos is: as inverdades nas memórias de Samuel Wainer, alegando que Wainer "foi criticado particularmente pelo jornalista Rivadávia Corrêa [sic] no livro", ${ }^{74}$ mas sem maior desenvolvimento sobre o teor da obra.

Retornando à mítica do meio jornalístico, a orelha da primeira edição (escrita por Augusto Nunes) demonstra tal efeito com um discurso que sacraliza a figura de Samuel e se expande a toda uma categoria profissional:

O jornalista Samuel Wainer foi um dos maiores repórteres brasileiros de todos os tempos, e isso já bastaria para que o país desejasse conhecer suas memórias. Grandes repórteres quase sempre se transformam em relevantes testemunhas da História, e à luz de seus relatos fica mais fácil compreender

\footnotetext{
${ }^{71}$ CASTRO, Moacir Werneck de. Samuel e Lacerda... Op. cit., p. 25.

72 ROUCHOU, Joëlle. Samuel... Op. cit., p. 26.

${ }^{73}$ Ibidem, p. 76.

${ }^{74}$ Ibidem, p. 48.
} 
como foi certa época num determinado país, e como eram os homens a quem coube desempenhar papéis decisivos, e como se deram exatamente os fatos.

Os membros dessa tribo fascinante, por sinal, são dotados de um instinto mediúnico que, aliado à sorte que contempla alguns eleitos, costuma levá-los a estar no lugar certo e na hora certa. ${ }^{75}$

A sorte, um suposto "instinto mediúnico", a condição de testemunha da História e a habilidade do profissional em farejar uma notícia espetacular se apresentam como elementos distintivos específicos de determinada categoria profissional e de seus eleitos, visando enaltecer o próprio meio e seus agentes perante outras categorias sociais, sobretudo o público leitor. Mas uma declaração de Wainer constante no "material bruto" analisado por Rouchou põe em cheque o supracitado fragmento no que diz respeito ao papel dos jornalistas em retratarem fatos decisivos e da exata maneira com que ocorreram. De acordo com Samuel, o jornalista não reproduz de maneira objetiva um fato observado, ele é um criador. Ainda com base no "material bruto", Rouchou acrescenta que "[p]ara ele, o bom jornalista não é necessariamente aquele que apura a matéria da maneira mais clara, verificando as fontes, não é aquele que informa melhor, mas aquele que dá a notícia primeiro". ${ }^{76}$ De certa forma, tanto os dizeres de Augusto Nunes quanto o relato de Wainer não deixam de carregar elementos próprios e inerentes à mítica do jornalismo, revelando demandas sociais específicas deste meio social e profissional. Se cada indivíduo observa, absorve e interpreta a realidade também com base em seu lugar social, tal interpretação é passível de ruídos relativos à alternação, às falhas de memória e às maneiras específicas de formalização da narrativa para atender a um mercado específico de bens simbólicos, conforme apresentamos ao longo deste trabalho.

\section{Considerações Finais}

Equívocos não intencionais e falhas de memórias autobiográficas que se manifestam em narrativas publicadas talvez causem estranhamento em alguns leitores. Tal situação não ignora, todavia, a possibilidade de ações e omissões deliberadas, talvez até mesmo convictas. O reconhecimento da origem diversa dos equívocos responde à necessidade de reduzir a assertiva segundo a qual toda a atividade no mundo e sobre o mundo é fruto de um cálculo prévio. Conforme apresentamos, a omissão da real nacionalidade de Wainer até 2005 carrega traços de uma ação deliberada, orquestrada pelo jornalista e colocada em prática com o apoio de sua filha, mas outros trechos contrapostos neste artigo não nos permitem afirmações seguras quanto às suas causas ou motivações.

Ao longo do artigo pudemos observar como algumas narrativas presentes em Minha Razão de Viver se apresentam frágeis frente a documentos ali citados (a entrevista de Getúlio Vargas efetivamente publicada em $O$ Jornal) ou frente à discordância de fontes mais ou menos

\footnotetext{
75 WAINER, Samuel. Minha Razão de... Op. cit. Grifos nossos.

${ }^{76}$ ROUCHOU, Joëlle. Samuel... Op. cit., p. 50.
} 
sincrônicas que oferecem uma versão alternativa (como as cartas de Alzira e Getúlio Vargas e o texto publicado por Assis Chateaubriand), evidenciando a constante necessidade de verificação e validação dos conteúdos trazidos nos relatos autobiográficos sem perder de vista as características e formulações inerentes a relatos desta natureza.

Se para Samuel o jornalista não reproduz mecanicamente um fato observado, sendo também um criador, o empreendimento levado adiante por este jornalista em colaboração com outros (como Augusto Nunes, Moacir Werneck de Castro, Marta Góes e Sérgio de Souza) não deixaria de trazer consigo sua parcela criativa. Esse gênero impuro, conforme atesta Dosse, construído exatamente na tensão (ambivalência e dualidade) entre a mimesis e a vida imaginada, se apresenta de maneira exemplar em Minha Razão de Viver, e talvez venha daí seu sucesso para com os mais diversos públicos.

Ainda que imprecisões ou equívocos se apresentem em determinados trechos e com referência a determinados episódios, Minha Razão de Viver permanece sendo uma importante fonte documental para o estudo da História da Imprensa e História Política do Brasil contemporâneo. E por mais que o cenário se torne nebuloso e dubitável no que se refere a certos fatos, locais, pessoas e datas, não há como negar o valor da narrativa de Samuel para o estudo de determinadas mentalidades e práticas temporal, social e profissionalmente circunscritas. 


\section{Referências Bibliográficas}

ARFUCH, Leonor. O espaço biográfico: dilemas da subjetividade contemporânea. Trad.: Paloma Vidal. Rio de Janeiro: EdUERJ, 2010.

BARBOSA, Marialva. História Cultural da Imprensa: Brasil, 1900-2000. 2a ed. Rio de Janeiro: Mauad X, 2007.

BERGER, Peter L. Excurso: Alternação e biografia (Ou: como adquirir um passado pré-fabricado). In: Perspectivas Sociológicas: uma visão humanística. Trad.: Donaldson M. Garschagen. 33a ed. Petrópolis, RJ: Vozes, 2014.

BERGER, Peter L.; LUCKMANN, Thomas. A sociedade como realidade subjetiva. In: A construção social da realidade: tratado de sociologia do conhecimento. Trad.: Floriano de Souza Fernandes. $35^{a}$ ed. Petrópolis, RJ: Vozes, 2013.

BOURDIEU, Pierre. A ilusão biográfica. In: BOURDIEU, Pierre. Razões Práticas: Sobre a teoria da ação. Trad.: Mariza Corrêa. $11^{\text {a }}$ ed. Campinas: Papirus. 2014.

CASTRO, Moacir Werneck de. Samuel e Lacerda ficaram fascinados um pelo outro. In: BARROS, Antonio Theodoro de Magalhães et al. A Última Hora de Samuel Nos Tempos de Wainer. Rio de Janeiro: ABICopim, 1993.

COSTA, Luís Ricardo Araujo da. Bota o retrato do velho Getúlio outra vez: a campanha presidencial de 1950 na imprensa do Rio de Janeiro. 2014. Dissertação (Mestrado em História) - Departamento de História, Instituto de Ciências Humanas e Filosofia, Universidade Federal Fluminense, Niterói (RJ).

DOSSE, François. O desafio biográfico: escrever uma vida. Trad.: Gilson César Cardoso de Souza. São Paulo: Ed. USP, 2009.

DUBY, Georges. A História continua. Trad.: Clóvis Marques. Rio de Janeiro: Zahar, 1993.

DUBY, Georges. Guilherme Marechal ou o melhor cavaleiro do mundo. Trad.: Renato Janine Ribeiro. Rio de Janeiro: Graal, 1987.

FAUSTO, Boris. Getúlio Vargas: o poder e o sorriso. São Paulo: Companhia das Letras, 2006.

LAURENZA, Ana Maria de Abreu. Lacerda x Wainer: O Corvo e o Bessarabiano. $2^{a}$ ed. São Paulo: Senac, 1998.

LEMOS, Renato. Samuel Wainer. (Verbete). In: Dicionário Histórico-Biográfico Brasileiro-DHBB. Rio de Janeiro: CPDOC/FGV, [s.d.]. Disponível em: http://www.fgv.br/cpdoc/acervo/dicionarios/verbetebiografico/wainer-samuel. Acesso em: 7 nov. 2018.

MORAIS, Fernando. Chatô: o rei do Brasil. São Paulo: Companhia das Letras, 1994.

NETO, Lira. Getúlio: Da volta pela consagração popular ao suicídio (1945-1954). São Paulo: Companhia das Letras, 2014.

NOVAES E CRUZ, Adelina; MOREIRA, Regina da Luz (orgs.). Volta ao poder: a correspondência entre Getúlio e a filha Alzira. Vol. 2: 1949 a 1950. Rio de Janeiro: FGV Ed.: Ouro sobre Azul, 2018.

ROUCHOU, Joëlle. Samuel: duas vozes de Wainer. 2a ed. Rio de Janeiro: UniverCidade, 2004.

SALMON, Lucy Maynard. Why is history rewritten. The North American Review, v. 195, n. 675, p. 225237, fev. 1912. Disponível em: https://www.jstor.org/stable/25119698. Acesso em: 16 set. 2018.

SCHACTER, Daniel L.; WAGNER, Anthony D. Aprendizado e memória. In: KANDEL, Eric R. et. al. Princípios de Neurociências. Trad.: Ana Lúcia Severo Rodrigues. 5a ed. Porto Alegre: AMGH, 2014. 
SOUZA, Rivadavia de. Botando os pingos nos is: as inverdades nas memórias de Samuel Wainer. Rio de Janeiro: Record, 1989.

WAINER, Samuel. Minha Razão de Viver: memórias de um repórter. $11^{a}$ ed. Rio de Janeiro: Record, 1988.

WAINER, Samuel. Minha Razão de Viver: memórias de um repórter. São Paulo: Planeta, 2005. 